Measuring the Impact of Product Placement with

Brand-related Social Media Conversations and Website Traffic

\author{
Beth L. Fossen \\ David A. Schweidel ${ }^{*}$
}

November 2018

Published in Marketing Science

${ }^{*}$ Beth L. Fossen (bfossen@indiana.edu) is Assistant Professor of Marketing at Indiana University's Kelley School of Business. David A. Schweidel (dschweidel@emory.edu) is Professor of Marketing at Emory University's Goizueta Business School. The authors thank the Marketing Science Institute for its financial support of this research. The authors also thank Michelle Andrews and seminar participants at the Darden School of Business at the University of Virginia, 2017 INFORMS Annual Meeting Conference, and 2018 AMA Winter Marketing Academic Conference for their helpful suggestions and comments. 


\title{
Measuring the Impact of Product Placement with \\ Brand-related Social Media Conversations and Website Traffic
}

\begin{abstract}
Advertisers are growing increasingly concerned about the ease with which traditional television advertising can be avoided. Product placement activities, where brands are visually and/or verbally incorporated into television and movies, have continued to grow. In contrast to television commercials that can be avoided by viewers, product placement is embedded in the programming itself and is more difficult to avoid. Despite its popularity, there is limited research in marketing that has investigated the impact of product placement. In this research, the authors investigate the relationship between product placement in television programs and the volume of social media activity and website traffic for the featured brand. Using data on nearly 3,000 product placements for 99 brands from the fall 2015 television season, the authors find that prominent product placement activities - especially verbal placements - are associated with increases in both online conversations and web traffic for the brand, with some evidence of decreasing returns at high levels of prominence. The authors also find that, for most placement modalities, television advertising occurring in close proximity to placement activities does not enhance these increases in online viewer engagement.
\end{abstract}

Keywords: Product placement, Branded entertainment, Social media, Brand strategy 


\section{Introduction}

Consumers' avoidance of advertising is on the rise (e.g., Hinz et al. 2011; Risselada et al. 2014). Just as marketers are facing increased difficulty reaching consumers with their messages online (e.g., eMarketer 2016; Vranica 2016), advances in technology have reshaped the television viewing landscape. Viewers are increasingly engaging in multi-screen activity, with an estimated $85 \%$ of U.S. consumers media multitasking while watching television (Nielsen 2015). While recent marketing research has shown that media multitasking can be leveraged to investigate responses to television advertising (e.g., Liaukonyte et al. 2015), there is some concern that this behavior can distract viewers from advertisements (e.g., Fossen and Schweidel 2017).

Technology has also facilitated the avoidance of traditional television advertising. The increased penetration and use of digital video recorders (DVRs) has provided viewers with the ability to skip ads. Nielsen (2016) estimates that $52 \%$ of U.S. households have a DVR, raising concerns about the reach and ultimate efficacy of traditional television advertising (e.g., Wilbur 2008). Television program consumption via streaming video on demand (SVOD) is also on the rise with an estimated 54\% of U.S. households having at least one SVOD subscription (Nielsen 2016). The growth of SVOD has further heightened advertisers' concerns as these platforms carry reduced advertising loads and enable consumers to consume content while limiting the amount of advertising to which they are exposed (Schweidel and Moe 2016).

While consumers may limit their exposure to television advertisements, it is difficult to avoid product placement activities that brands undertake (e.g., Cowley and Barron 2008; Karniouchina et al. 2011; Schweidel et al. 2014), as these placements are embedded in the program content. Product placement also offers brands the potential to promote their products in a more natural way (Russell 2002) that is less expensive than traditional television advertising (Katz 2013, pg. 117; Russell and Belch 2005). This attractiveness paired with the shift in television viewers' 
consumption behaviors has contributed to the continued growth of product placement activities. In the U.S., for example, spending on product placements grew 14\% in 2017 to $\$ 8.78$ billion and is estimated to top $\$ 10$ billion in 2018 (Mandese 2018).

Despite its growth, limited empirical research has examined the impact of product placement efforts on television, which has exacerbated practitioners' challenges with measuring the effectiveness of placements (Gianatasio 2014; Russell and Belch 2005). Media multitasking during television viewing provides an opportunity to observe viewers' reactions to programming via their online behaviors. However, while early research on such cross-media effects has investigated the impact of television advertising on online behaviors (e.g., Fossen and Schweidel 2017; Joo et al. 2014; Liaukonyte et al. 2015), this stream of work has not yet considered the relationship between consumers' online activities and placements embedded in programming.

In this research, we examine the relationship between a brand's product placement activities on television and two measures of engagement that manifest as online behaviors: (1) the volume of online word-of-mouth (WOM) mentioning the brand and (2) the volume of traffic to the brand's website. In particular, we explore how the product placement modality may impact the relationship between product placement and viewers' online engagement with the brand. We also consider how product placement occurring in close temporal proximity to advertising may influence this relationship. In doing so, we investigate two primary research questions. How does product placement activity relate to changes in online WOM and web traffic for the featured brand? And, to what extent does product placement work independently or synergistically with traditional television advertising to associate with changes in these online behaviors?

Using data on 2,806 product placements for 99 brands that aired in the fall 2015 television season, the results from multiple analyses indicate that product placement can be associated with 
increased online engagement, with the strength of this relationship depending on placement modality. In particular, more prominent placements relate to larger increases in online chatter and web traffic for the featured brand, with some evidence of decreasing returns at high levels of prominence. Overall, our results support that product placement is a means by which marketers can reach consumers who have become adept at avoiding television advertising.

Additionally, our results suggest that advertising does not enhance the relationship between product placement and increases in viewers' online behaviors. While we find evidence that the main effects of advertising and product placement can be related to increases in online WOM and traffic, their interaction effects are primarily negative or not significant. As proximity to advertising can enhance the prominence of placements, these findings may provide further support that placement effectiveness decreases at the high levels of prominence, highlighting the importance of coordination between marketers, networks, and television content creators.

The remainder of this research proceeds as follows. We next review literature related to product placement and television advertising's impact on consumer behavior. We then describe the data, examine model-free evidence of the relationship between product placement and online brand WOM and web traffic, and discuss our empirical analyses. We present the results and conclude with a discussion of the implications of our findings and directions for future research.

\section{Related Literature}

We primarily draw on two streams of work. We first provide a review of the research on product placement. We then review work that has examined the impact of television advertising on online behaviors and discuss how product placement may influence online WOM and web traffic.

\subsection{Product Placement's Impact on Consumers}


Prior work has examined the ways in which product placements affect consumers from multiple perspectives. O'Guinn and Shrum (1997) demonstrated that what viewers see on television can affect their perceptions of reality. Those who reported higher amounts of television viewing tended to have higher estimates for the prevalence of behaviors that are featured on television, such as ownership of luxury cars and swimming pools. The authors suggest that exposure to products and behaviors on television may make them more accessible in memory, resulting in the belief that they are more common. This demonstrates television's ability to shape consumers' perceptions. Given this, the use of television as a means of influencing consumers' decisions should come as no surprise. Product placement stands in contrast to traditional advertising by being embedded into programming. While advertising offers one approach of reaching consumers, it is readily apparent to viewers that they are being exposed to a persuasion attempt, which can trigger a defensive reaction (e.g., Friestad and Wright 1994). In contrast, product placement offers a more natural way for marketers to advertise their products (Russell 2002).

Past research on product placement has shown that it can influence consumer behavior. In their review of audiences' responses to product placement, Balasubramanian et al. (2006) identify three types of effects: cognition (e.g., recognition, recall), affect (e.g., brand attitudes), and conation (e.g., brand choice, purchase intention). While research has often measured the effect of placement on cognition and affect, there is limited work with conative outcomes. Moreover, existing research on the effectiveness of product placement has produced mixed results, with effectiveness varying based on the outcome selected and placement characteristics.

While the findings have been mixed, research on product placement has illustrated that prominence is a key determinant of the placement's effectiveness (e.g., Gupta and Lord 1998; Law and Braun 2000; Russell 2002; van Reijmersdal 2009). This prominence is often operationalized 
using placement modality (e.g., Gupta and Lord 1998; Law and Braun 2000; Russell 2002). Specifically, audiovisual placements are argued to be more prominent than verbal and visual placements because they spur both verbal and visual processing, resulting in information being better recognized and recalled (e.g., Bressoud et al. 2010; Paivio 1979; Russell 2002; Van Reijmersdal et al. 2009). Additionally, verbal placements have been argued to be more prominent than visual placements because they require higher plot integration (e.g., an actress saying a brand's name versus the brand appearing in the background) (Russell 2002; Homer 2009) and because verbal information typically grabs attention better and encourages more elaboration than visual information (e.g., Gupta and Lord 1998; Homer 2009; Posner et al. 1976; Russell 2002). This leads to verbal placements being processed more deeply than visual placements (Balasubramanian et al. 2006; Gupta and Lord 1998; Russell 2002). Beyond modality, placement prominence may be further heightened by plot connection, location on screen, repetition, shortterm proximity to television advertising, and placement duration (e.g., Balasubramanian et al. 2006; Bressoud et al. 2010; Gupta and Lord 1998; Homer 2009; Karniouchina et al. 2011; Law and Braun 2000; Russell 2002; Verhellen et al. 2016).

Given that viewers must be exposed to a placement for it to impact their behavior, several studies have found that more prominent placements are more effective at influencing consumer behavior than less prominent placements. For example, audiovisual placements have been found to be better recalled and spur higher abnormal returns compared to verbal and visual placements (e.g., Bressoud et al. 2010; Law and Braun 2000; Wiles and Danielova 2009), and verbal placements have been found to be better recalled than visual placements (e.g., Gupta and Lord 1998; Russell 2002). These positive effects of prominence are said to arise because prominence increases the probability that a viewer is exposed to a placement and makes it easier to process 
relative to other program stimuli (e.g., Balasubramanian et al. 2006).

However, placement prominence may backfire if its overtness makes obvious the persuasive intent or interferes with the plot. In such cases, high levels of placement prominence may invoke persuasion knowledge that can distract, irritate, or spur counter-argumentation, leading to a more negative viewing experience (e.g., Balasubramanian et al. 2006; Friestad and Wright 1994; Homer 2009; Karniouchina et al. 2011; Russell 2002; Russell et al. 2017). Indeed, research has illustrated that placements can have negative impacts on brand attitudes if they appear overtly prominent, such as when they are paired with a disclosure (Boerman et al. 2015), out of place in the plot (Russell 2002), notably repeated (Homer 2009), or paired with a preceding advertisement prime (Cowley and Barron 2008). Other studies have shown that while more prominent audiovisual placements spur better cognitive outcomes, they do not necessarily improve affective outcomes (Cowley and Baron, 2008; Russell 2002; van Reijmersdal, 2009) or conative outcomes (Law and Braun 2000) beyond less prominent placements.

Additional investigations suggest that increasing prominence from low to moderate levels positively impacts placement effectiveness, but increasing prominence from moderate to high levels offers no additional benefit and may spur the negative effects of invoking persuasion knowledge noted above (Homer 2009). Such decreasing returns of placement prominence have been found to manifest as either negative effects of highly prominent placements on consumer behavior or as statistically indistinguishable effects between different placement modalities that vary in prominence. Russell (2002) operationalizes prominence through plot connection and finds that while visual placements with high plot connection are better recalled than visual placements with lower plot connection, there is no significant difference between higher and lower plot verbal placements. This finding may occur because the increased prominence of plot connection does not 
offer additional benefits over the increased prominence of the verbal modality. Similarly, Gupta and Lord (1998) find that audiovisual placements offer no additional benefit over prominent visual placements. They contend that this may occur because the necessary prominence for recall has already been met by the prominent visual placement and that the incremental value of the audiovisual modality is undetectable.

Overall, the mixed findings on product placement across outcomes measured and placement characteristics are echoed from the practitioners' perspective (e.g., Gianatasio 2014; Russell and Belch 2005). Our limited understanding of the efficacy of product placement is exasperated by the lack of research on the effects of placements on consumers' actions and decisions. Two such studies, Wiles and Danielova (2009) and Karniouchina et al. (2011), both link placements in movies to stock market performance and find a positive relationship, although the latter work finds that more recent movie placements are less effective than placements that occurred when the advertising method was new to consumers. To the best of our knowledge, no similar studies have been done to broadly examine the effectiveness of television product placement on behavioral outcomes. In this investigation, we aim to address the dearth in research examining the impact of product placement on television on conative outcomes by assessing the extent to which product placement may relate to changes in online consumer behaviors.

\subsection{Product Placement, Online WOM, and Web Traffic}

A separate body of research has begun to investigate how television advertising impacts online behaviors. These voluntary consumer behaviors occur in close proximity to television media, allowing for identification of the media's impact on the behavior of interest through a quasiexperimental design (e.g., Fossen and Schweidel 2017; Lewis and Reiley 2013; Liaukonyte et al. 2015). Because of this proximity, these online behaviors may be better suited to studying ad 
effectiveness than sales or traditional survey measures, which take longer to observe (Lewis and Reiley 2013). Research also contends that the online activities generated by media multitasking viewers are good proxies for sales (e.g., Lewis and Nguyen 2015; Lewis and Reiley 2013). Overall, this body of work illustrates that television viewers' online behavior during programming can be leveraged to explore the effectiveness of television media.

Research on cross-media effects has shown that television advertising can have a positive impact on viewers' immediate online activity, including the volume of online WOM about the advertised brand (Fossen and Schweidel 2017), volume of online search for the brand (Joo et al. 2014), and volume of web traffic and purchases on the brand's website (Liaukonyte et al. 2015). While this research presents evidence that television advertising can influence online behaviors, the relationship between product placement and online activities has not been considered. Given television's ability to shape consumers' perceptions (e.g., O'Guinn and Shrum 1997), we expect that product placement has the potential to influence online behavior. In this research, we leverage viewers' media multitasking to investigate the relationship between product placement and two measures of consumer engagement that manifest as online behaviors: the volume of online WOM mentioning the brand and the volume of traffic to the brand's website.

We focus on these two measures for three key reasons. First, both online chatter and browsing are voluntary consumer behaviors that viewers engage in immediately following television media (Fossen and Schweidel 2017; Liaukonyte et al. 2015), allowing us to link the timing of online behavior to specific placements. Second, as noted above, online WOM and web traffic are good proxies for sales. This is important in our data as the majority of placements are for brands for which measuring the link between television media and sales is challenging due to the low frequency of purchases (e.g., automobiles). Lastly, these two outcomes capture different 
aspects of consumer engagement online, which is beneficial for a broad study of product placement activities on television. Decisions to post social media content are spurred by two main types of utility: intrinsic utility (e.g., inherent satisfaction from engaging in online conversations) and image-related utility (e.g., motivation to influence other's perception of oneself) (Toubia and Stephen 2013). On the other hand, visiting a brand's website is primarily motivated by information search or purchasing goals (Liaukonyte et al. 2015; Xu et al. 2017).

We anticipate that product placement will be associated with increases in both online WOM and web traffic for the featured brand. Based on prior research, we also expect placement prominence to influence this relationship. We anticipate that prominence will be particularly important in a media multitasking context where viewers are switching attention between multiple screens. In such a context, a verbal component to a product placement may be necessary for a viewer to process the placement. Verbal components also facilitate viewers' chat or search activities about the featured brand as they explicitly mention the brand name. Media multitasking may also dampen the perception that prominent placements are annoying, distracting, and/or a promotional ploy because viewers are too cognitively burdened to invoke persuasion knowledge (Yoon et al. 2012). We treat the possible decreasing returns of prominence on placement effectiveness as an empirical question in our investigation.

We operationalize placement prominence using modality and the placements' proximity to advertising. For the former, we identify four categories of product placement in the data, varying from low to high prominence: implied visual placement, direct visual placement, verbal placement, and audiovisual placement (Table 1). We also consider the placement's proximity to advertising from the same brand, as pairing advertising with product placement may increase the prominence of the placement (e.g., Cowley and Barron 2008; Russell et al. 2017; Schweidel et al. 2014). By 
accounting for advertising and exploring its interaction with placements, we also investigate the extent to which product placement operates independently or synergistically with television advertising to associate with changes in online chatter and web traffic for the brand.

\section{[Insert Table 1 about Here]}

While previous research indicates that pairing a placement with advertising can increase the prominence of a placement, assessments of placement effectiveness are mixed. Some studies have found that pairing a placement with advertising can lead to better cognitive outcomes, such as recall and recognition, than the placement alone (Balasubramanian et al. 2006; Davtyan et al. 2016; Wiles and Danielova 2009). Schweidel et al. (2014) find that a placement preceding an ad by the same brand can reduce channel-changing behavior, possibly because the placement had a positive effect on brand attitudes. However, other studies have found that increasing the prominence of a placement with advertising may have a negative impact on placement effectiveness. Priming a placement with a preceding ad by the same brand can eliminate the placement's positive impacts on brand attitudes, as this strategy can signal the persuasive intent to viewers (Cowley and Barron 2008). Russell et al. (2017) similarly find that while exposure to an ad before a placement can draw more attention to the placement, it also activates persuasion knowledge, which increases the perceived commercialization of the program and adversely affects the viewing experience. Overall, this research indicates that advertising may affect placement effectiveness. We treat the nature of this relationship as an empirical question.

While we anticipate that the hypothesized relationships will hold for both online WOM and web traffic, there may be some variation in how product placement relates to changes in these outcomes as they are different consumer behaviors. As noted above, online chatter is more likely to be motivated by intrinsic or image-related utility goals, while visiting a brand's website is more 
likely to be motivated by information-seeking or consumption goals. Thus, placements for brands aligned with intrinsic or image-related utility (e.g., entertainment products) may spur more online WOM, while placements for brands aligned with information-seeking or consumption goals (e.g., newspapers, retailers) may spur more web traffic in the short-term.

The activity a media multitasking viewer engages in may also depend on the device used, with smartphone/tablet-use more motivated by communication goals and laptop/PC-use more motivated by information-seeking and purchasing goals (e.g., Google 2012). Using devices with smaller screen sizes is more physically challenging (Ghose et al. 2013; Melumad et al. 2018; Xu et al. 2017), and it is possible that this increased cognitive challenge, in turn, may dampen the negative effects of placement prominence (Yoon et al. 2012). Thus, online behaviors that are more likely to occur on a smartphone, such as online chatter, may be less negatively impacted by placement prominence than activities that are more likely to occur on devices with larger screen sizes, such as web browsing. Overall, we anticipate that these differences will influence the relationship that product placement has with the outcome measures.

\section{Data}

\subsection{Product Placement and Television Advertising Data}

Data on product placement were gathered from Kantar Media's Stradegy. Our data contain 2,806 placements for 99 brands that aired on 77 primetime (8:00-11:00 PM), broadcast programs during the fall 2015 television season (September through December 2015). Stradegy provides data on a number of characteristics for the placements including the brand, date and time the placement airs (at the second-level), program and pod in which the placement airs, length, modality, if a character interacted with the placement, and if the placement was referenced as a sponsor. We also construct a cumulative measure of placement activity to control for the number of previous placements a 
brand had in a given program. To control for the number of viewers exposed to a placement, we collect data on audience size from comScore, Inc.'s TV Essentials database, which includes viewing data collected for more than 20 million U.S. households. We use the U.S. audience size estimate for the 30 -second interval (the granularity provided by TV Essentials) in which the placement begins airing and ends airing. We investigate the relationship between these placements and social media mentions of the brand and traffic to the brands' website by focusing on these responses to the initial airings of the placements ${ }^{1}$.

To account for the brand's traditional television advertising activity, we pair the product placement data with second-level data on television advertising expenditures by the 99 brands from Stradegy. We collect data on ad expenditures by these brands for both national and local advertising instances on broadcast channels during the same timeframe as the placement data. We employ data on advertising costs to account for the size of the audience exposed to the ad.

\subsection{Social Media and Web Traffic Data}

To investigate the relationship between product placement and online chatter, we collect data on second-level Twitter mentions for the 99 brands from Crimson Hexagon, a certified Twitter partner ${ }^{2}$. We focus on Tweets because the majority of public social media conversations about television occur on Twitter (Schreiner 2013). Twitter mentions for the brand were gathered by tallying Tweets that mention the brand or its products and/or include the twitter handle of the brand or product. To explore the relationship between product placement and web traffic, we gather data on web browsing behavior from comScore, Inc.'s Web Behavior database. These data contain

\footnotetext{
${ }^{1}$ Pacific programming is not an initial broadcasting as it airs three hours after Eastern/Central programming. Thus, this data focuses on reactions to placements on Eastern/Central programming, which air to $76 \%$ of the U.S. population (based on U.S. Census Bureau 2015 State Population Estimates).

${ }^{2}$ The second-level data from Crimson Hexagon are derived by accessing the list of Twitter posts, which includes the time of each post. The list includes up to 10,000 posts per day that match the query. If there are more than 10,000 posts matching the query on a given day, Crimson Hexagon takes a random sample of 10,000 posts from that day.
} 
second-level online browsing behavior for a panel of 100,000 active U.S. internet users. We track new sessions to the websites of the 99 brands in the product placement data.

\subsection{Descriptive Statistics}

Table 2 shows descriptive statistics for product placement and advertising across placement modality. Online Appendix Tables 1 and 2 list the 99 brands featured in the placements and the 77 programs in which the placements air, and Online Appendix Table 3 presents correlations among the variables in the analyses. The majority of the product placement activities in our data are for automobiles. The brands with the most placements are Ford (492), Chevrolet (383), Microsoft (263), Apple (234), and Fitbit (126). The majority of the product placement activities in the data are direct visual (66\%), followed by implied visual (23\%), verbal (8\%), and audiovisual (3\%). We see variation within brands in terms of the modality of placement activities and the number of programs in which the placements air (Online Appendix Table 1). We also see variation in ad spending around the placements, both across and within placement modality types (Table 2). While we find no strong correlations between the ad spending and placement measures (Online Appendix Table 3), we do see that ad spending post-audiovisual placements is higher than its pre-placement spending levels (Table 2). This may suggest coordination among advertisers, television networks, and program creators for audiovisual placements, but we do not see similar evidence of coordination for the other three product placement types (Table 2$)^{3}$.

\footnotetext{
${ }^{3}$ Our data does not code paid, coordinated placements versus unpaid placements, a limitation we acknowledge and discuss. Our data does allow us to probe their prevalence, as we later discuss, and suggests that their occurrence is rare. For robustness, we estimate a series of alternative models to show that placements that may be associated with increased coordination between program and advertiser do not drive our main findings. Specifically, we estimate models in which we (1) exclude placements that are labeled as sponsors, (2) exclude audiovisual placements, (3) exclude longer placements, and (4) exclude placements that have post-placement ad spending. Results from these alternative analyses are statistically consistent with our proposed model (see Online Appendix).
} 
Table 3 shows descriptive statistics across placement characteristics. Of note, the average placement is about one minute in length. Additionally, $43 \%$ of the placements air without any preceding placement activity by the same brand within a given program. Furthermore, the change in number of viewers from the start of the placement to its end is minimal. Lastly, we see evidence in Table 3 that placement characteristics vary across modality type.

[Insert Tables 2 and 3 Here]

\section{Preliminary Analyses}

\subsection{Model-free Evidence}

Table 4 illustrates the relationship between product placement and changes in online chatter and web traffic for the featured brand. On average, placements in our data are associated with a $16 \%$ increase in online WOM and a 13\% increase in web traffic in the ten-minute period post-placement (compared to the ten-minute period pre-placement). Assessing the mean and distribution of change, we also see that more prominent placements might be associated with increases in these online activities more strongly than less prominent placements, as verbal and audiovisual placements are the modalities most strongly associated with increases in online chatter and web traffic. However, the estimates in Table 4 have sizable standard deviations.

[Insert Table 4 and Figure 1 Here]

Figure 1 illustrates a different view of these changes using time-series plots around placement airings ${ }^{4}$. We see that most placement activities precede an increase in online brand chatter, with verbal and audiovisual placements preceding the largest increases ${ }^{5}$. Consistent with

\footnotetext{
${ }^{4}$ There is high variation in the change in online WOM and web traffic across placement incidences. For example, the range between the 2.5- and 97.5-percentile for online WOM (web traffic) taken one minute after an audiovisual placement is $[0,26]([0,4563])$. Given the high range, we do not present the percentiles in Figure 1.

5 The decrease in WOM following direct visual placements in Figure 1 is consistent with the distribution of changes presented in Table 4 and may arise due to the variation across brands, an effect we control for in our analyses.
} 
Table 4, Figure 1 also shows that verbal and audiovisual placements appear to precede the largest increases in web traffic at the brand's website post-placement. Like the sizeable standard deviations in Table 4, however, Figure 1 also illustrates considerable noise in the raw data.

Table 5 illustrates the relationship among placement and advertising and our outcomes. Considering all observations, we see that higher advertising spend pre- and post-placement may be associated with larger increases in online chatter and higher advertising spend pre-placement may be associated with larger increases web traffic; however, Table 5 also suggests that the nature of this relationship varies with placement modality. The estimates also have large standard deviations, limiting the model-free evidence we can conclude from these estimates.

Overall, Tables 4-5 and Figure 1 indicate that product placement activity may associate with immediate increases in online chatter and web traffic for placed brands and that this relationship may be influenced by placement modality. However, the model-free evidence reveals considerable variation across brands ${ }^{6}$ and does not allow us to disentangle if product placement and advertising relate to changes in online viewer engagement independently or synergistically. We explore this relationship in more detail in our empirical analyses.

[Insert Table 5 Here]

\subsection{Brand-level Analysis}

Model Framework. Table 4 and Figure 1 present preliminary evidence that product placement has meaningful associations with increases in online WOM and web traffic. To further assess these associations, we conduct a preliminary brand-level analysis to investigate the relationship among

\footnotetext{
${ }^{6}$ For robustness, we estimate our main placement-level analysis while excluding the top $1 \%$ or the top $5 \%$ of observations in terms of post-placement WOM and in terms of post-placement web traffic. Results from these alternative analyses are statistically consistent with our main analysis, indicating that the outliers in terms of postplacement WOM and web traffic are not driving the results. We also conduct an analysis in which we exclude audiovisual placements and also find results statistically consistent with our proposed model.
} 
online behaviors and placements and advertising, the use of which by the brand varies over time. For each brand $b$ and ten-minute interval $t$ on day $d$, we let $Y_{b t d l}=\log \left(1+W O M_{b t d}\right)$ and $Y_{b t d 2}=\log (1+$ Traffic $b t d$ ), where $W_{\text {OMtd }}$ is the number of Twitter mentions for brand $b$ on day $d$ in time interval $t$ and Trafficbtd denotes the number of visits to brand $b$ 's website on day $d$ in time interval $t$. We assume that $Y_{b t d j} \sim \mathrm{N}\left(\mu_{b t d j}, \sigma_{j}^{2}\right)$ for $j=1$ and 2, and that $\mu_{b t d j}$ is a function of brand $b$ 's product placement activity on day $d$ in time interval $t$.

To allow for product placement activity from earlier in the evening to influence online activities later in the evening, we construct stock variables for each placement modality. We assume that, for each of the four modalities (denoted $z$ ), PlacementStock $k_{b t d z}=\delta_{z} \cdot$ PlacementStock $_{b(t-}$ 1)dz + Placement $_{b t d z}$, where Placement $_{b t d z}$ is the average size of the audience tuned to the program at the time that brand $b$ is featured in placement modality $z$ in interval $t$ on day $d$ (in $1,000,000 \mathrm{~s}$ of viewers). The parameter $\delta_{z}$ reflects the extent to which earlier placements of modality $z$ carry over and impact later online behaviors. We similarly construct a stock measure of advertising by brand $b$, where $A d \operatorname{Stock}_{b t d}=\delta_{5} \cdot A d S t o c k_{b(t-1) d}+A d_{b t d}$ in which $A d_{b t d}$ is the amount spent on television advertising by brand $b$ on day $d$ in time interval $t$ (in $\$ 1,000,000 \mathrm{~s})^{7}$. We also control for the amount of online activity in the prior ten-minute window as well as the time of day, day of the week, and month. For $j=1$ and 2 , we specify $\mu_{b t d j}$ as:

$$
\begin{aligned}
& \mu_{b t d j}=\alpha_{b j}+\sum_{k=1}^{4} \beta_{k, j} \text { PlacementStock }_{b t d k}+\beta_{5, j} \text { AdStock }_{b t d}+ \\
& \sum_{k=6}^{9} \beta_{k, j} \text { AdStock }_{b t d} \text { PlacementStock }_{b t d k}+\tau_{j} Y_{b(t-1) d j}+X_{b t d} \theta_{j}
\end{aligned}
$$

The term $\alpha_{b 1}\left(\alpha_{b 2}\right)$ captures variation across brands in the amount of online WOM (web traffic). The coefficients $\beta_{1,1}-\beta_{4,1}\left(\beta_{1,2}-\beta_{4,2}\right)$ capture the main effect of product placement on online

\footnotetext{
${ }^{7}$ We assume that the values of advertising and placement stock variables are reset to 0 each day, and we calculate these variables using data beginning at 7:00 PM (one hour before primetime starts).
} 
WOM (web traffic). $\beta_{6,1}-\beta_{9,1}$ and $\beta_{6,2}-\beta_{9,2}$ account for product placement's interaction with advertising. The coefficient $\tau_{1}\left(\tau_{2}\right)$ accounts for the effect of online WOM (web traffic) in the previous ten-minute interval on that in the current ten-minute interval. Lastly, $\theta_{1}$ and $\theta_{2}$ capture the variation in online behavior related to the day and time blocks (daily half-hour intervals, baseline $=$ Sunday 8:00-8:29 PM) and month $($ baseline $=$ December $)$. The coefficients are estimated via maximum likelihood estimation.

Model Comparison. We compare this brand-level model to one that omits product placement. For online WOM, the likelihood ratio test comparing the model that includes the main effects of product placement and its interaction with advertising $(L L=-142,054)$ against the model that omits product placement $(L L=-142,072)$ indicates that the incorporation of product placement improves model fit $(-2 \log \Lambda=37.7, p<.001)$. For web traffic, the model that includes product placement and its interaction with advertising $(L L=-47,741)$ also yields better model fit than the model that omits product placement $(\mathrm{LL}=-47,754 ;-2 \log \Lambda=26.0, p=.001)$. This suggests that both online behaviors are better explained by the models that incorporate product placement.

Results. The results from the brand-level analysis are presented in Table 6. Focusing first on online WOM, our analysis suggests that advertising as well as verbal and audiovisual product placements are associated with increased online WOM. These findings are consistent with work that shows that more prominent placement activities are more effective (e.g., Bressoud et al. 2010; Law and Braun 2000; Wiles and Danielova 2009). We see some possible evidence of decreasing returns of placement prominence as we find that verbal placements are associated with larger increases in online WOM than the more prominent audiovisual placements. With regards to web traffic, we similarly find that advertising and as well as verbal and audiovisual product placements are associated with increased in web traffic for the advertised brand. Overall, these findings 
underscore the importance of placement prominence in moderating effectiveness. This analysis suggests that less prominent placements (implied visual and direct visual) do not meaningfully associate with changes in online chatter and web traffic for the placed brand while more prominent placements (verbal and audiovisual) do relate to such increases.

We also see that the relationship between product placement and online behaviors can be moderated by advertising. Three out of the four interactions in both the online WOM and web traffic models are either negative or not significant, suggesting that advertising occurring in close proximity with product placement usually does not enhance the relationship between the placements and online viewer engagement. The two exceptions to this conclusion are advertising occurring near audiovisual placements in terms of associating with increases in online WOM or near direct visual placements in terms of associating with increases in web traffic. As close proximity to advertising can enhance placement prominence, these results may suggest that placement effectiveness decreases when the salience of the brand is made too high.

[Insert Table 6 about Here]

Both the model-free evidence and our brand-level analysis suggest that product placement activities are associated with increases in online behavior, with placement modality influencing the strength of this relationship. These analyses, however, are not without their limitations. As they do not focus on a specific advertising or product placement instances, these analyses do not consider the program in which the brand-related exposure occurred. Additionally, while the analysis focuses on the modality of placement, further placement characteristics are not considered. To account for these factors and to better attribute changes in online behaviors to product placement activities, we next present our placement-level analysis.

\section{Placement-level Analysis}




\subsection{Model Framework}

We next examine how online chatter and web traffic change around placement incidences. This placement-level investigation uses a quasi-experimental design (e.g., Liaukonyte et al. 2015) to provide a more detailed analysis of the relationship between product placements and their characteristics and the outcomes of interest. For each incidence of product placement $i$, we model the volume of Tweets that mention the featured brand and the volume of traffic to the featured brand's website post-placement as follows:

$$
\begin{aligned}
& \operatorname{LogPostWOM}_{i}=\rho_{0}+\pi_{b[i], 1}+\phi_{p[i], 1}+\rho_{1} \cdot \text { LogPreWOM}_{i}+\sum_{k=1}^{3} \rho_{1+k} \cdot \\
& \text { AudienceSize }_{i} \cdot\left(\text { Modality }_{i}=k\right)+\sum_{k=1}^{2} \rho_{4+k} \cdot \text { AdSpend }_{i k}+\sum_{k=1}^{3} \sum_{j=1}^{2} \rho_{6+3(j-1)+k} \\
& \text { AudienceSize }_{i} \cdot\left(\text { Modality }_{i}=k\right) \cdot \text { AdSpend }_{i j}+X_{i} \lambda+\varepsilon_{i, 1} \\
& \text { LogPostTraffic }_{i}=\gamma_{0}+\pi_{b[i], 2}+\phi_{p[i], 2}+\gamma_{1} \cdot \text { LogPreTraffic }_{i}+\sum_{k=1}^{3} \gamma_{1+k} \cdot \\
& \text { AudienceSize }_{i} \cdot\left(\text { Modality }_{i}=k\right)+\sum_{k=1}^{2} \gamma_{4+k} \cdot \text { AdSpend }_{i k}+\sum_{k=1}^{3} \sum_{j=1}^{2} \gamma_{6+3(j-1)+k} \cdot \\
& \text { AudienceSize }_{i} \cdot\left(\text { Modality }_{i}=k\right) \cdot \text { AdSpend }_{i j}+X_{i} \kappa+\varepsilon_{i, 2}
\end{aligned}
$$

where $\operatorname{LogPostWOM}_{i}\left(\operatorname{LogPost}_{\text {Traffic }}\right)$ is the log of the volume of Twitter mentions corresponding to the brand in placement $i$ (number of visits to website of the brand in placement $i$ ) that occurs between when the placement starts airing until ten minutes after the placement. LogPreWOMi (LogPreTraffic $\left.c_{i}\right)$ is the log of the volume of Twitter mentions corresponding to the brand in placement $i$ (number of visits to website of the brand in placement $i$ ) that occurs ten minutes prior to the placements airing until the placement starts airing. We use log specifications as there is large variance in these measures across brands ${ }^{8}$.

\footnotetext{
${ }^{8}$ We take the log plus one to avoid taking the log of zero. We test a number of different specifications of the dependent variables including two specifications where the dependent variables are constructed as percentage changes measures and twelve alternative specifications where we vary the time window from one to sixty minutes. All of these alternative models produce highly consistent results (see Online Appendix).
} 
$\rho_{0}$ and $\gamma_{\mathrm{o}}$ are the intercepts. The brand-specific fixed effects are captured by $\pi_{b(i), l}$ and $\pi_{b(i), 2}$, where $b(i)$ denotes the brand that appears in placement $i$. Similarly, the program-specific fixed effects are $\phi_{p(i), 1}$ and $\phi_{p(i), 2}$, where $p(i)$ denotes the program in which placement $i$ appears ${ }^{9}$. The coefficients $\rho_{2-4}\left(\gamma_{2-4}\right)$ reflect the differences in $\operatorname{LogPostWOM}$ (LogPostTraffici $i$ ) attributable to variation in the modality of placement $i$. We let Modality $=1$ indicate a direct visual placement, Modality $=2$ indicate a verbal placement, and Modality $=3$ indicate an audiovisual placement. We let a placement that is an implied visual serve as our baseline. Thus, $\rho_{2-4}$ and $\gamma_{2-4}$ reflect differences between an implied visual placement and placements of the other modalities. We weight placement modality by audience size so that our operationalization of product placement accounts for the number of viewers exposed to the placement ${ }^{10}$.

The coefficients $\rho_{5}, \rho_{6}, \gamma_{5}$, and $\gamma_{6}$ account for the impact of pre- and post-placement advertising from the brand in placement $i$ that occur in the same program as placement $i$ (AdSpend $_{i 1}$ and $\operatorname{AdSpend}_{i 2}{ }^{11}$. For both pre- and post-placement advertising, we consider advertising that occurs within ten minutes of placement $i$. We further consider how advertising may interact with placements to relate to the outcomes. These interactions are captured by coefficients $\rho_{7-} \rho_{12}$ and $\gamma_{7}-$ $\gamma_{12}$. Lastly, the vectors $\lambda$ and $\kappa$ accounts for the impact of placement characteristics and other control variables denoted $X_{i}$, which includes time the placement airs (quarter-hour increments), length of the placement ${ }^{12}$, program pod (i.e., program segment) in which the placement airs,

\footnotetext{
${ }^{9}$ For identification, we set $\pi_{1,1}=0, \pi_{1,2}=0$ (for the brand Acura) and $\phi_{1,1}=0, \phi_{1,2}=0$ (for the program 2 Broke Girls).

${ }^{10}$ Audience size is expressed in $1,000,000$ of viewers. We test an alternative operationalization in which incidences are not weighted by audience size, which yields consistent results but does not improve model fit. We also estimate a model in which we include a control for the change in audience size from the start to the end of the placement. This model does not improve model fit compared to the proposed model, and the control is not significant.

${ }^{11}$ Ad expenditures are expressed in $\$ 1,000,000.30 \%$ (26\%) of the placements have pre-(post-)placement advertising that occurs within ten-minutes of the placement's airing.

${ }^{12} \mathrm{As}$ the data include a number of lengthy placements, we run two alternative models where we estimate equations (2)-(3) while (1) excluding the bottom and top 5\% of placements based on length and (2) excluding the top 25\% of placements based on length. Results from both these alternative models are statistically consistent with those of the proposed model, indicating that the outlier placements in terms of placement length are not driving the results.
} 
cumulative placement activity in the program (both a linear and quadratic term), ad expenditures by the brand on different broadcast channels, and if the placement was interacted with by a character or was announced as a sponsor. We estimate equations (2)-(3) using maximum likelihood estimation with cluster-robust standard errors at the brand level.

Following the identification strategy used in research on the effects of television on online behaviors (Fossen and Schweidel 2017; Liaukonyte et al. 2016), we use narrow time windows around the placement to better attribute any changes in online chatter and web traffic to the focal variables of interest, focusing on ten-minute windows in our analysis ${ }^{13}$. By controlling for online activity in the ten-minute window pre-placement, this analysis captures how placement activity relates to changes in the brand's online WOM and web traffic post-placement, above and beyond the brand's baselines of these online behaviors in the pre-placement period.

These granular time windows are beneficial because it is likely that most advertisers do not know the specific time at which a placement containing their brand will air, a point we argue for two key reasons. First, though our data do not indicate which placements are paid, coordinated placements (those that are more likely to be strategic decisions), we can probe their prevalence as such placement activities are likely to be integrated more prominently. Only $8 \%$ of the placement incidences are sponsors, a placement that is an in-program reference to an advertising sponsor, and only $3 \%$ of placements are integrated into the program with both a clear verbal and visual component. Second, even advertisers that pay for placements may not know the precise timing of when it will air (within or across episodes), as many coordinated placement agreements are seasonlong relationships. ${ }^{14}$ Additionally, Russell and Belch (2005) illustrate the complex nature of the

\footnotetext{
${ }^{13} \mathrm{We}$ test twelve different time windows varying the pre- and post-placement lengths from one to sixty minutes. We also vary the time windows for ad spend so that they match the time windows associated with the dependent variables. Our key results are highly consistent in these alternative analyses (see Online Appendix).

${ }^{14}$ For example, an illustrative product placement agreement for MTV's Jersey Shore can be accessed via the SEC
} 
product placement industry, bringing into question the volume of paid placement activity that is truly strategic. Given that it is likely that most placements in our data are unpaid and uncoordinated with the brand and that there are uncertainties with paid placements concerning their strategic nature and when they will air, it is within reason to assume that the majority of brands do not know the granular time window in which a placement will air.

Advertisers also do not know the precise time at which their television ads will air (Fossen and Schweidel 2017; Liaukonyte et al. 2016). The ad buying process restricts advertisers' control over when and where their ads air (Katz 2013). The timing of when an ad will air is rarely stated in advertiser-network contracts, and even which program the ad will air on is not often stipulated (Liaukonyte et al. 2016). Networks further restrict any jurisdiction over when an advertisement will air by ordering ads at random across commercial breaks and by using "make-good" policies that allow ads that did not reach the number of viewers paid for by the advertisers to be re-run on different programs on different days (Wilbur et al. 2013).

Given these characteristics of product placement and advertising, the airing of a product placement can serve as an appropriate shock to viewers' short-term online activity, which we use to explore how placement activities relate to changes in online behavior. Given that it is very challenging for advertisers to know granular time windows in which their product placement and advertising activities will air, it is unlikely that advertisers could push out additional promotional messages within a ten-minute window that could inflate the effect sizes in ${ }^{15}$.

website at https://www.sec.gov/Archives/edgar/data/1489256/000116169711000855/ex 10-1.htm. The agreement specifies a period of "organic, on-camera product placement" from September 10, 2011 thru March 10, 2012.

${ }^{15}$ This argument is strongest for narrow time windows, as longer time windows increase concerns about advertisers' ability to synchronize marketing efforts with the timing of placements. We considered alternative time windows ranging from one to sixty minutes and find results highly consistent with our main model (see Online Appendix). As an additional robustness check, we exclude all Tweets from the Twitter account(s) of the advertised brand as well as all Tweets that contain \#ad, \#sponsored, or \#paid. Given the rare occurrence of such Tweets in the ten-minute windows around placements, the results from this alternative analysis are nearly identical to the proposed model. 


\subsection{Results}

Model Comparison. To explore if product placement meaningfully relates to changes in online behavior to support the results from our brand-level analysis, we first compare our proposed model to several alternatives on model fit in Table 7. The model fit comparison illustrates that placements meaningfully explain online WOM and web traffic. Specifically, the model with no advertising or placement variables explains $78.5 \%$ and $84.1 \%$ of the variation in online WOM and web traffic, respectively ${ }^{16}$. Incorporating the placement variables increases the explained variation of online WOM and web traffic to $86.4 \%$ and $92.0 \%$. Thus, we see that placement activity meaningfully explains online chatter and web traffic about the placed brand. Our final model also incorporates advertising and the placement-advertising interactions. We focus our placement-level results discussion on this model specification as it is our best fitting model.

\section{[Insert Table 7 about Here]}

Product Placement and Placement Characteristics. We examine the relationship between product placement and viewers' online behaviors in Table $8^{17}$. We first focus on how placement modalities may differ in their relationship with online WOM and web traffic compared to implied visual placements, the least prominent modality. Consistent with our earlier findings that placements have a meaningful relationship with online engagement and that prominence plays a key role, we find strong evidence for verbal placements and weak evidence for audiovisual placements that these placement activities are more strongly associated with increases in online WOM than implied visual placements. We also find weak evidence for direct visual placements and strong evidence for verbal placements that these placement activities are more strongly related to increases in web traffic than implied visual placements.

\footnotetext{
16 The explained variation is likely high due to the inclusion of LogPreWOM $i$ and LogPreTraffic.

${ }^{17}$ Online Appendix Tables 4-6 show the estimates of the effects of time, brand, and program.
} 
While these findings are highly consistent with our brand-level analysis, the results for audiovisual placements in the placement-level analysis were not expected. The findings that (1) audiovisual placements are only marginally associated with increases in online WOM relative to implied visual placements and (2) audiovisual placements do not significantly differ from implied visual placements in terms of their relationship with web traffic may occur for two reasons. First, these results could provide evidence for the decreasing returns of placement prominence on effectiveness. Our findings are consistent with past research that has found that (1) increasing prominence from low to moderate levels positively impacts placement effectiveness while increasing prominence to higher levels can spur negative effects and (2) the decreasing returns of prominence can manifest as statistically indistinguishable effects between highly prominent versus less prominent modalities (e.g., Gupta and Lord 1998; Homer 2009; Russell 2002). Our finding that online chatter appears to be less impacted by possible decreasing returns of placement prominence appears consistent with the notion that behaviors that tend to occur on a smartphone, like online chatter, may be less negatively impacted by placement prominence than activities that tend to occur on larger devices, such as web browsing. Second, these results concerning audiovisual placements in the placement-level analysis are influenced by the improved set of placement characteristics in the placement-level analysis. In particular, many of the placement characteristics with meaningful relationships with online viewer behavior (Table 8), which we discuss next, are commonly used with audiovisual placements (Table 3).

Overall, consistent with the brand-level analysis, the findings from the placement-level analysis underscore the importance of placement prominence in influencing effectiveness ${ }^{18}$.

\footnotetext{
${ }^{18}$ We estimate a series of alternative models to see if higher quality placements drive the main findings. We estimate models in which we exclude placements that are sponsors, audiovisual placements, longer placements, or placements that have post-placement ad spending within ten minutes of the placement. Results from these analyses are statistically consistent with our proposed model, indicating that higher quality placements do not drive our main findings (see
} 
Across all of our analyses, we find the strongest evidence for verbal placements in terms of relating to increases in viewers' online behaviors.

\section{[Insert Table 8 about Here]}

Beyond modality, we find that placements that air later in the program are less strongly associated with increases in online WOM than those that air earlier in the program ${ }^{19}$. This finding is consistent with Fossen and Schweidel (2017) who find that online chatter about television ads marginally reduces during later ad breaks in the program. Reduced online brand WOM later in the program may occur because viewers increase their program-related chatter during this time as the show content becomes more interesting. Additionally, we find support that placements that are interacted with by a real person in a show (e.g., Blake Shelton on The Voice) are associated with larger increases in online WOM post-placement. This finding may relate to research on the effectiveness of celebrity endorsements and human brands (e.g., Thomson 2006).

We also find that referencing a placement as an advertising sponsor - compared to a placement that does not use this strategy - is associated with less web traffic post-placement. This finding may present additional evidence of the decreasing returns of placement prominence, as pairing a placement with a sponsorship disclosure can significantly increase prominence (Boerman et al. 2015). Table 8 also shows several non-significant effects of placement characteristics, which seem consistent with research that has found that placement characteristics related to plot integration and repetition have limited impact on affective or conative outcomes (Law and Braun 2000; Verhellen et al. 2016; Wiles and Danielova 2009).

\footnotetext{
Online Appendix).

${ }^{19}$ Interpretations of placement effectiveness as a factor of when the placement airs should also consider the effect of cumulative placements (Table 8) and time (Online Appendix Table 4) (see Online Appendix Figure 1).
} 
Product Placement and Advertising. We see some evidence that advertising by the same brand following a placement, particularly when it occurs in the same program, is associated with increased online WOM post-placement (Table 8). For the interactions among advertising and placement activities, we find that half of the interactions in each model indicate a significant negative relationship. With the exception of the interaction effect of pre-placement advertising and the verbal modality on web traffic, the estimated interaction coefficients are smaller in magnitude than the advertising coefficients, indicating that the interactions tend to dampen the impact of advertising on online behavior. The other half of the advertising-placement interactions suggest a non-significant relationship. As proximity to advertising can enhance placement prominence, these effects may provide further support for the decreasing returns of placement prominence. These results are consistent with the brand-level analysis finding that advertising occurring in close temporal proximity with product placement usually does not enhance the relationship between the placement activities and online viewer engagement.

Scenario Analyses. To better illustrate the combined impact of product placement and advertising on online behavior, we conduct a scenario analysis for three brands (Ford, Microsoft, and Amazon) in which we vary the placement modality and the amount and timing of advertising. We use the average values for the brands' placements for the independent variables in equations (2)-(3) (e.g., average placement length, etc.). We calculate percentage changes in the two online behaviors relative to implied visual placements and show the results in Table 9.

[Insert Table 9 Here]

We find that verbal and audiovisual placements are most associated with increases in online WOM, regardless of ad spending. Verbal and audiovisual placements are associated with as much as an $18 \%$ or $32 \%$ increase, respectively, in online WOM over implied visual placements. 
Additionally, verbal placements are most strongly related to increases in web traffic, regardless of the ad spending strategy, with as much as a $47 \%$ increase in traffic over implied visual placements. While we see substantial differences in online behavior across placement modalities, online behavior is less sensitive to variation in ad spending, consistent with our finding that advertising occurring in close temporal proximity with product placement rarely enhances the relationship between the placement activities and online viewer engagement ${ }^{20}$.

\section{Discussion}

Using data on product placement, television advertising, social media activity, and web traffic, we investigate how exposure to brands in television content may relate to changes in online behaviors. We find that prominent product placement activities - especially verbal placements - relate to immediate increases in online WOM and website traffic for the placed brand, with some evidence of decreasing returns at high levels of prominence. While prior experimental studies have offered conflicting results, our research is among the first evidence that product placements can relate to detectable and quantifiable changes in consumers' online behaviors, suggesting that online WOM and traffic may provide marketers with a means of evaluating their product placements. Moreover, our research suggests that offline methods may serve as a means to reach consumers and encourage them to engage with brands online.

Our results also suggest television advertising occurring close to placements rarely enhances these increases in online engagement. While we find that both the main effects of

\footnotetext{
${ }^{20}$ To assess if the main results arise spuriously, we conduct a falsification test in which we only include those placement incidences that air to smaller audiences (bottom $25^{\text {th }}$ percentile in terms of audience size), as we would expect less of an effect of placement in such cases. We find no significant main effects of placement at the $95 \%$ confidence level in this analysis (see Online Appendix). These results may provide support suggesting that our key findings do not arise spuriously but also may occur because the falsification test is underpowered.
} 
advertising and product placement can be associated with increases in online WOM and traffic, their interaction does not enhance (and often times dampens) the positive relationship with online engagement. These results highlight the importance of coordination between marketers, networks, and content creators so that marketing investments are not squandered.

\subsection{Implications for Marketers, Television Networks, and Television Content Creators}

For marketers considering product placement, our analyses suggest that placements can be used to reach consumers, even those who have become more adept at avoiding television advertising. Moreover, we demonstrate how consumers' online behaviors may be leveraged to assess placement effectiveness. The findings on the role of placement prominence suggest potential value for increased coordination between marketers, program creators, and television networks, as embedding a verbal or audiovisual placement in a program may require such coordination.

With consumers engaging in media multitasking, marketers should be particularly mindful of the impact of the verbal aspect of product placement. While consumers' visual attention may shift from screen to screen, verbal (and audiovisual) placements offer a means of reaching them regardless of the screen on which their eyes are focused at a given moment. Verbal placements may require less coordination or be less costly than audiovisual placements. In deciding among different types of product placement, as well as coordinating these efforts with advertising, marketers must ultimately weigh the potential benefits against the financial costs.

\subsection{Limitations and Directions for Future Research}

As technology assists consumers' desires to avoid marketing messages, the lines between marketing and content are becoming increasingly blurred. Our data do not indicate whether placements are paid or unpaid, precluding us from examining how the financial arrangement affects consumers' perceptions and their awareness of being exposed to marketing. Future research 
may incorporate such factors. Even though our data contains a mix of both paid and unpaid placements, we still find that placement activities relate to changes in online behavior ${ }^{21}$.

Future work is also needed to assess consumers' exposure to marketing messages across devices and platforms, including mobile video consumption. While our analysis focuses on changes in online WOM and web traffic in temporal proximity to placements, viewers are increasingly in control of when and how they consume content. Our data is limited in that it is not single-source nor does it allow us to directly observe an individual's behavior across devices and platforms. Such single-source, cross-device or cross-platform data would facilitate gaining a more complete picture of content consumption and exposure to marketing. As our analysis focuses on live viewing behavior and does not consider time-shifted viewing, our results may offer a conservative estimate of how placements relate to shifts in online WOM and web traffic.

While we focus on the volume of online WOM as an outcome measure, future research may delve into WOM content ${ }^{22}$. Future work may also delve into how the effectiveness of placements vary across brands ${ }^{23}$. While we examine brands from multiple industries, such research may be best served by taking a narrower slice of brands or product categories. Another limitation of our approach is that our assessment of the change in online behaviors is restricted to differences observed in the short-term. Thus, our analysis is not intended to assess long-term effects of product placement. Future work may consider the degree to which the effects of placements that we have

\footnotetext{
${ }^{21}$ We estimate a series of alternative models to show that placements that are associated with increased coordination between program and advertiser do not drive our main findings. We estimate models in which we exclude placements that are sponsors, audiovisual placements, longer placements, or placements that have post-placement ad spending. Results from these analyses are statistically consistent with our proposed model (see Online Appendix).

${ }^{22}$ For robustness, we consider the valence of online WOM. We find that the relationship between placements and online WOM is primarily related to increases in non-negative WOM (see Online Appendix).

${ }^{23}$ As an alternative analysis, we incorporated measures of visibility and excitement from the brand database collected by Lovett et al. (2014), as they may relate to prominence and consumers' media multitasking activity about brands, respectively. These measures were only available for 51 brands in our data, and we did not find evidence that they moderated the relationship between placements and viewers' online behaviors.
} 
documented persist and contribute to enduring shifts in brand perceptions. Such an investigation would also allow for the study of placement effectiveness throughout the customer journey, ultimately concluding with its impact on purchasing.

Lastly, we use narrow time windows around product placements to study the relationship between placements and online behaviors (e.g., Fossen and Schweidel 2017; Liaukonyte et al. 2015). While our robustness analyses help make the case that we have limited the influence of confounding factors that may occur around placements, such as brand-generated social media activity, it is challenging to account for all such factors. This is a common limitation of empirical research on the effectiveness of television media, as detailed by Lewis and Reiley (2013). However, if such confounding factors exist in our context while consistently occurring at similar levels around placement airings, the effect sizes of our results should be reasonable ones to expect for airing a product placement on television. While large-scale randomized field experiments are not currently possible given the state of television technology (Lewis and Rao 2015; Lewis and Reiley 2013), such experiments or comparable lab experiments could be a fruitful avenue of future research to continue investigating the effectiveness of product placement activities on television.

In summary, we present the first empirical investigation to quantify the relationship between product placement activities and television using viewers' online behaviors. Through model-free evidence, a brand-level analysis, and a placement-level analysis, we present consistent evidence that prominent product placement activities - especially verbal placements - are associated with increases in online chatter and web traffic for the brand. We hope this investigation spurs marketers to take note of the potential to measure product placement's effectiveness using online viewer engagement and that it encourages additional explorations into factors that may enhance or mitigate the effectiveness of product placement. 


\section{References}

Balasubramanian, S. K., J. A. Karrh, and H. Patwardhan (2006), "Audience Response to Product Placements: An Integrative Framework and Future Research Agenda," Journal of Advertising, 35(3), 115-141.

Boerman, S. C., E. A. van Reijmersdal, and P. C. Neijens (2015), "Using Eye Tracking to Understand the Effects of Brand Placement Disclosure Types in Television Programs," Journal of Advertising, 44(3), 196207.

Bressoud, E., J. Lehu, and C. A. Russell (2010), "The Product Well Placed: The Relative Impact of Placement and Audience Characteristics on Placement Recall," Journal of Advertising Research, 50(4), 374-385.

Cowley, E. and C. Barron (2008), "When Product Placement Goes Wrong: The Effects of Program Liking and Placement Prominence," Journal of Advertising, 37(1), 89-98.

Davtyan, D., K. Stewart, and I. Cunningham (2016), "Comparing Brand Placements and Advertisements on Brand Recall and Recognition," Journal of Advertising Research, 56(3), 299-310.

eMarketer (2016), "US Ad Blocking to Jump by Double Digits This Year," (June 21), https://www.emarketer.com/Article/US-Ad-Blocking-Jump-by-Double-Digits-This-Year/1014111.

Fossen, B. L. and D. A. Schweidel (2017), "Television Advertising and Online Word-of-Mouth: An Empirical Investigation of Social TV Activity," Marketing Science, 36(1), 105-123.

Friestad, M. and P. Wright (1994), "The Persuasion Knowledge Model: How People Cope with Persuasion Attempts," Journal of Consumer Research, 21(1), 1-31.

Ghose A., Goldfarb A., S. P. Han SP (2013), "How is the Mobile Internet Different? Search Costs and Local Activities," Information Systems Research, 24(3), 613-631.

Gianatasio, D. (2014), "RuPaul Dresses up Product Placement: Reality Shows like Drag Race, Top Chef, Project Runway Cast Brands in a Starring Role," Adweek, (August 10), http://www.adweek.com/news/advertising-branding/rupaul-dresses-product-placement-159385.

Google (2012), "The New Multi-screen World: Understanding Cross-platform Consumer Behavior," (August), https://www.thinkwithgoogle.com/advertising-channels/mobile/the-new-multi-screen-world-study/.

Gupta, P. B, and K. R. Lord (1998), "Product Placement in Movies: The Effect of Prominence and Mode on Audience Recall," Journal of Current Issues and Research in Advertising, 20(1), 47-59.

Hinz, O., B. Skiera, C. Barrot, and J. U. Becker (2011), "Seeding Strategies for Viral Marketing: An Empirical Comparison," Journal of Marketing, 75 (November), 55-71.

Homer, P. M. (2009), "Product Placements," Journal of Advertising, 38(3), 21-32.

Joo, M., K. C. Wilbur, B. Cowgill, and Y. Zhu (2014), "Television Advertising and Online Search," Management Science, 60(1), 56-73.

Karniouchina, E. V., C. Uslay, and G. Erenburg (2011), "Do Marketing Media Have Life Cycles? The Case of Product Placement in Movies," Journal of Marketing, 75(3), 27-48.

Katz, H. E. (2013), The Media Handbook: A Complete Guide to Advertising Media Selection, Planning, Research, and Buying. New York: Routledge.

Law, S. and K. A. Braun (2000), "I'll Have What She's Having: Gauging the Impact of Product Placements on Viewers," Psychology \& Marketing, 17(12), 1059-1075.

Lewis, R. A. and D. Nguyen (2015), "Display advertising's competitive spillovers to consumer search," Quantitative Marketing and Economics, (13), 93-115.

Lewis, R. A. and D. H. Reiley (2013), "Down-to-the-Minute Effects of Super Bowl Advertising on Online Search Behavior," $14^{\text {th }}$ ACM Conference on Electronic Commerce, 9(4), 639-656.

Lewis, R.A. and J. M. Rao (2015), "The Unfavorable Economics of Measuring the Returns to Advertising," The Quarterly Journal of Economics, 130(4), 1941-1973

Liaukonyte, J., T. Teixeira, and K. C. Wilbur (2015), "Television Advertising and Online Shopping," Marketing Science, 34(3), 311-330.

Lovett, M., R. Peres, and R. Shachar (2014), “A Data Set of Brands and Their Characteristics," Marketing Science, 33(4):609-617.

Mandese, J. (2018), "Product Placement Poised To Top \$10 Billion: Report Cites Fewer, More Valuable Deals Including Upfronts, Netflix," MediaPost, (June 13), https://www.mediapost.com/publications/article/320675/productplacement-poised-to-top-10-billionrepor.html. 
Melumad, S., J. J. Inman, and M. T. Pham (2018), "Emotional Gist: How Smartphone Use Changes UserGenerated Content," working paper.

Nielsen (2015), "New America. New Consumers," (July 21), http://www.nielsen.com/us/en/insights/news/2015/new-america-new-consumers.html.

Nielsen (2016), "The Nielsen Total Audience Report: Q3 2016," http://www.nielsen.com/content/dam/corporate/us/en/reports-downloads/2016-reports/q3-2016-totalaudience-report.pdf.

O'Guinn, T. C. and L. J. Shrum (1997), "The Role of Television in the Construction of Consumer Reality," Journal of Consumer Research, 23(4), 278-294.

Onishi, H. and P. Manchanda (2012), "Marketing Activity, Blogging and Sales," International Journal of Research in Marketing, 29(3), 221-234.

Paivio, Alan (1971). Imagery and Verbal Processes. New York: Holt, Rinehart, and Winston, Inc.

Posner, M. I., M. J. Nissen, and R. Klein (1976), "Visual Dominance: An Information Processing Account of Its Origins and Significance," Psychological Review, 83 (2), 157-171.

Risselada, H., P. C. Verhoef, and T. H.A. Bijmolt (2014), "Dynamic Effects of Social Influence and Direct Marketing on the Adoption of High-Technology Products," Journal of Marketing, 78 (March), 52-68.

Russell, C. A. (2002), "Investigating the Effectiveness of Product Placements in Television Shows: The Role of Modality and Plot Connection Congruence on Brand Memory and Attitude," Journal of Consumer Research, 29(3), 306-318.

Russell, C. A., D. Russell, A. Morales, and J. Lehu (2017), "Hedonic Contamination of Entertainment How Exposure to Advertising in Movies and Television Taints Subsequent Entertainment Experiences," Journal of Advertising Research, 57(1), 38-52.

Russell, C. A. and M. Belch (2005), "A Managerial Investigation into the Product Placement Industry," Journal of Advertising Research, 45(1), 73-92.

Schweidel, D. A., N. Z. Foutz, and R. J. Tanner (2014), "Synergy or Interference: The Effect of Product Placement on Commercial Break Audience Decline," Marketing Science, 33(6), 763-780.

Schweidel, D. A. and W.W. Moe (2016), Binge Watching and Advertising," Journal of Marketing, 80(5), 1-19.

Schreiner, T. (2013), "Amplifiers Study: The Twitter Users Who Are Most Likely to Retweet and How to Engage Them," Twitter, (January 10), https://blog.twitter.com/2013/amplifiers-study-the-twitter-userswho-are-most-likely-to-retweet-and-how-to-engage-them.

Thomson, Matthew (2006), "Human Brands: Investigating Antecedents to Consumers' Strong Attachments to Celebrities," Journal of Marketing, 70 (3), 104-119.

Toubia, O. and A. T. Stephen (2013), "Intrinsic vs. Image-Related Utility in Social Media: Why Do People Contribute Content to Twitter?," Marketing Science, 32(3), 368-392.

Van Reijmersdal, E., P. Neijens, and E.G. Smit (2009), “A New Branch of Advertising: Reviewing Factors That Influence Reactions to Product Placement," Journal of Advertising Research, 49(4), 429-449.

Verhellen, Y., N. Dens, and P. De Pelsmacker (2016), "Do I Know You? How Brand Familiarity and Perceived Fit Affect Consumers' Attitudes Towards Brands Placed in Movies," Marketing Letters, 27, 461-471.

Vranica, S. (2016), “Advertisers Try New Tactics to Break Through to Consumers," The Wall Street Journal, (June 19), http://www.wsj.com/articles/advertisers-try-new-tactics-to-break-through-to-consumers1466328601.

Wilbur, K. C. (2008), "How the Digital Video Recorder (DVR) Changes Traditional Television Advertising," Journal of Advertising, 37(1), 143-149.

Wiles, M. A. and A. Danielova (2009), "The Worth of Product Placement in Successful Films: An Event Study Analysis," Journal of Marketing, 73(4), 44-63.

Xu, K. J. Chan, A. Ghose, S. P. Han (2017), "Battle of the Channels: The Impact of Tablets on Digital Commerce," Management Science, 63(5),1469-1492.

Yoon, S., Y.K. Choi, and S.Song (2011), "When Intrusive Can be Likable,” Journal of Advertising, 40, 63-76. 
Table 1: Placement Modalities

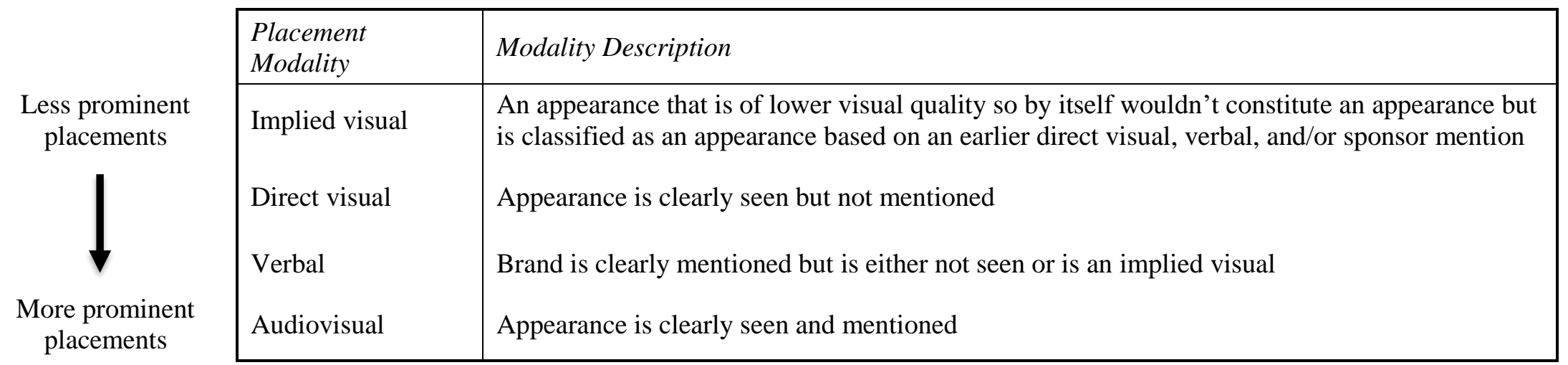

Note: Following past research on product placement, as discussed in section 2.1, we classify verbal placements as more prominent than direct visual placements (e.g., Balasubramanian et al. 2006; Gupta and Lord 1998; Homer 2009; Posner et al. 1976; Russell 2002).

Table 2: Number of Product Placement Incidences and Advertising Spend across Placement Modality

\begin{tabular}{|c|c|c|c|c|c|c|c|c|c|c|c|c|c|c|c|c|}
\hline \multirow{3}{*}{$\begin{array}{c}\text { Placement } \\
\text { Modality }\end{array}$} & \multirow{3}{*}{$\begin{array}{l}\text { Number of } \\
\text { Placements }\end{array}$} & \multicolumn{8}{|c|}{ Ad Spend Pre-placement } & \multicolumn{7}{|c|}{ Ad Spend Post-placement } \\
\hline & & \multicolumn{4}{|c|}{ Same Channel } & \multicolumn{4}{|c|}{ Other Broadcast Channels } & \multicolumn{4}{|c|}{ Same Channel } & \multicolumn{3}{|c|}{ Other Broadcast Channels } \\
\hline & & Min & Mea & (SD) & Max & Min & Mea & $(\mathrm{SD})$ & Max & Min & Mean & (SD) & Max & Min & Mean (SD) & $\operatorname{Max}$ \\
\hline Implied visual & 638 & 0.00 & 0.01 & $(0.04)$ & 0.30 & 0.00 & 0.03 & $(0.08)$ & 0.82 & 0.00 & 0.01 & $(0.03)$ & 0.35 & 0.00 & $0.03 \quad(0.09)$ & 1.07 \\
\hline Direct visual & 1848 & 0.00 & 0.01 & $(0.05)$ & 0.71 & 0.00 & 0.03 & $(0.10)$ & 1.33 & 0.00 & 0.01 & $(0.05)$ & 0.87 & 0.00 & 0.03 & 1.58 \\
\hline Verbal & 226 & 0.00 & 0.01 & $(0.04)$ & 0.34 & 0.00 & 0.01 & $(0.06)$ & 0.59 & 0.00 & 0.01 & $(0.05)$ & 0.47 & 0.00 & $(0.08)$ & 0.87 \\
\hline Audiovisual & 94 & 0.00 & 0.02 & $(0.05)$ & 0.28 & 0.00 & 0.02 & $(0.08)$ & 0.52 & 0.00 & 0.05 & $(0.13)$ & 0.97 & 0.00 & $(0.08)$ & 0.50 \\
\hline All observations & 2806 & 0.00 & 0.01 & $(0.04)$ & 0.71 & 0.00 & 0.03 & $(0.09)$ & 1.33 & 0.00 & 0.01 & $(0.05)$ & 0.97 & 0.00 & $0.03 \quad(0.09)$ & 1.58 \\
\hline
\end{tabular}

Note: Ad spend is shown in $\$ 1,000,000$ s. Ad spend pre-placement on the same channel (other broadcast channels) is the volume of ad spend by the brand in the placement on same channel (other broadcast channels) in which the placement airs between ten minutes before the placement airs till it airs. Ad spend postplacement on the same channel (other broadcast channels) is the volume of ad spend by the brand in the placement on same channel (other broadcast channels) in which the placement airs between when the placement airs till ten minutes after it airs. 
Table 3: Placement Characteristics across Placement Modality

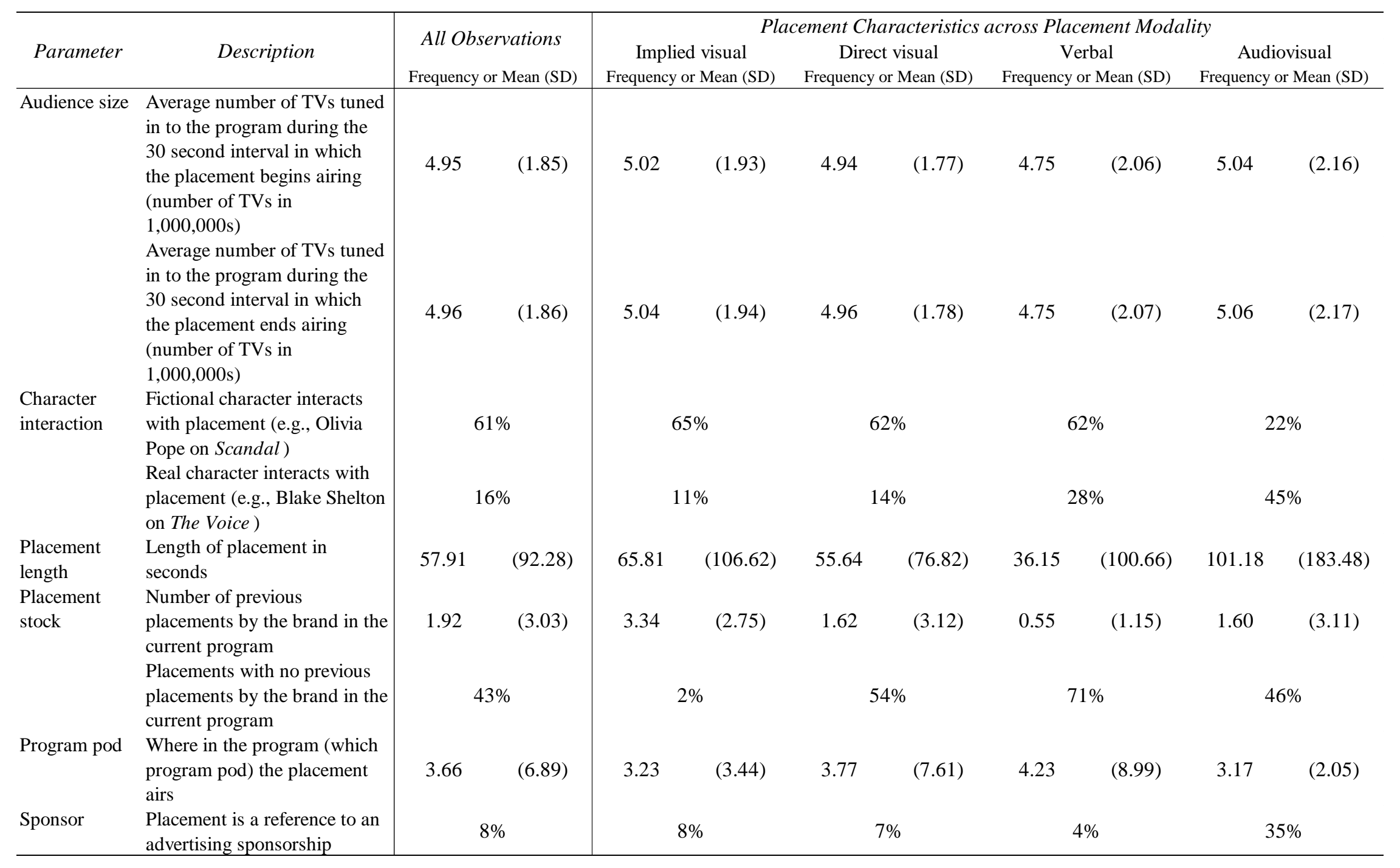


Table 4: Model-free Evidence of the Relationship between Product Placement and Brand-related Social Media Activity and Website Traffic

\begin{tabular}{|c|c|c|c|c|c|c|c|c|c|c|c|c|c|c|c|c|}
\hline \multirow{2}{*}{$\begin{array}{l}\text { Placement } \\
\text { Modality }\end{array}$} & \multirow{2}{*}{$\begin{array}{l}\text { Volume of } \\
\text { WOM Post- } \\
\text { placement }\end{array}$} & \multirow{2}{*}{$\begin{array}{c}\text { Volume of } \\
\text { Web Traffic } \\
\text { Post- } \\
\text { placement }\end{array}$} & \multicolumn{7}{|c|}{ Change in WOM Pre-to Post-Placement } & \multicolumn{7}{|c|}{ Change in Web Traffic Pre- to Post-Placement: } \\
\hline & & & $\mathrm{Me}$ & $(\mathrm{SD})$ & Min & $\begin{array}{c}1^{\text {st }} \\
\text { Quartile }\end{array}$ & Median & $\begin{array}{c}3^{\text {rd }} \\
\text { Quartile }\end{array}$ & Max & Mea & (SD) & Min & $\begin{array}{c}1^{\text {st }} \\
\text { Quartile }\end{array}$ & Median & $\begin{array}{c}3^{\text {rd }} \\
\text { Quartile }\end{array}$ & Max \\
\hline Implied visual & 35,187 & 2,906 & $10 \%$ & $(70 \%)$ & $-85 \%$ & $-20 \%$ & $0 \%$ & $25 \%$ & $1106 \%$ & $10 \%$ & $(56 \%)$ & $-75 \%$ & $0 \%$ & $0 \%$ & $0 \%$ & $700 \%$ \\
\hline Direct visual & 94,474 & 6,434 & $9 \%$ & $(62 \%)$ & $-92 \%$ & $-23 \%$ & $-2 \%$ & $25 \%$ & $700 \%$ & $12 \%$ & & $-86 \%$ & $0 \%$ & $0 \%$ & $0 \%$ & $700 \%$ \\
\hline Verbal & 11,604 & 523 & $61 \%$ & $(263 \%)$ & $-75 \%$ & $-16 \%$ & $13 \%$ & $48 \%$ & $3100 \%$ & $21 \%$ & $(71 \%)$ & $-86 \%$ & $0 \%$ & $0 \%$ & $31 \%$ & $450 \%$ \\
\hline Audiovisual & 5,380 & 239 & $81 \%$ & $(311 \%)$ & $-60 \%$ & $-23 \%$ & $6 \%$ & $36 \%$ & $1477 \%$ & $28 \%$ & $(82 \%)$ & $-67 \%$ & $0 \%$ & $0 \%$ & $12 \%$ & $500 \%$ \\
\hline All observations & 146,645 & 10,102 & $16 \%$ & $(113 \%)$ & $-92 \%$ & $-22 \%$ & $0 \%$ & $26 \%$ & $3100 \%$ & $13 \%$ & $(60 \%)$ & $-86 \%$ & $0 \%$ & $0 \%$ & $0 \%$ & $700 \%$ \\
\hline
\end{tabular}

Note: The volume numbers in columns two and three are the summed volumes of WOM and Web traffic in the ten-minute window post-placement. The percentage changes in WOM and traffic were calculated as: (activity in ten-minute post-placement - activity in ten-minute pre-placement)/ (activity in ten-minute pre-placement +1$)$. Note that the web traffic data from comScore, Inc.'s Web Behavior Database illustrated in Table 4 comes from a panel of 100,000 active U.S. internet users.

Table 5: Model-free Evidence of the Relationship among Product Placement, Television Advertising and Brand-related Social Media Activity and Website Traffic

Change in WOM Pre- to Post-Placement

Change in Web Traffic Pre- to Post-Placement

\begin{tabular}{|c|c|c|c|c|c|c|c|c|}
\hline \multirow{3}{*}{$\begin{array}{c}\text { Placement } \\
\text { Modality }\end{array}$} & & \\
\hline & \multicolumn{2}{|c|}{ Ad spend pre-placement } & \multicolumn{2}{|c|}{ Ad spend post-placement } & \multicolumn{2}{|c|}{ Ad spend pre-placement } & \multicolumn{2}{|c|}{ Ad spend post-placement } \\
\hline & $\begin{array}{c}\text { Below median } \\
\text { Mean }(\mathrm{SD})\end{array}$ & $\begin{array}{c}\text { Above median } \\
\text { Mean (SD) }\end{array}$ & $\begin{array}{c}\text { Below median } \\
\text { Mean }(\mathrm{SD})\end{array}$ & $\begin{array}{c}\text { Above median } \\
\text { Mean (SD) }\end{array}$ & $\begin{array}{c}\text { Below median } \\
\text { Mean (SD) }\end{array}$ & $\begin{array}{c}\text { Above median } \\
\text { Mean (SD) }\end{array}$ & $\begin{array}{c}\text { Below median } \\
\text { Mean }(\mathrm{SD})\end{array}$ & $\begin{array}{l}\text { Above median } \\
\text { Mean (SD) }\end{array}$ \\
\hline Implied visual & $5 \%(44 \%)$ & $19 \%(103 \%$ & & & $7 \%(58 \%)$ & & & \\
\hline Direct visual & $10 \%(66 \%)$ & $7 \%(50 \%)$ & $8 \%(63 \%)$ & $12 \%(60 \%)$ & $12 \%(62 \%)$ & $11 \%(50 \%)$ & $14 \%(61 \%)$ & $7 \%(50 \%)$ \\
\hline Verbal & $68 \%(288 \%)$ & $28 \%(54 \%)$ & $67 \%(280 \%)$ & $20 \%(55 \%)$ & $19 \%(67 \%)$ & $29 \%(90 \%)$ & $22 \%(72 \%)$ & $14 \%(64 \%)$ \\
\hline Audiovisual & $10 \%(44 \%)$ & $255 \%(546 \%)$ & $4 \%(44 \%)$ & $245 \%(516 \%)$ & $13 \%(56 \%)$ & $65 \%(118 \%)$ & $19 \%(65 \%)$ & $47 \%(109 \%)$ \\
\hline All observations & $14 \%(107 \%)$ & $19 \%(125 \%)$ & $13 \%(104 \%)$ & $23 \%(134 \%)$ & $12 \%(61 \%)$ & $15 \%(57 \%)$ & $14 \%(62 \%)$ & $10 \%(56 \%)$ \\
\hline
\end{tabular}

Note: Table 5 shows ad spend by the brand in the placement on the same channel in which the placement airs (see note under Table 2 for description of these variables). See note under Table 4 about calculation of percentage changes. The median value for pre- and post-placement advertising is $\$ 0$, so below median ad spend occur when ad spend is $\$ 0$. 
Table 6: Relationship among Product Placement, Television Advertising, and Brand-related Social Media Activity and Website Traffic in Brand-level Analysis

\begin{tabular}{|c|c|c|c|c|c|c|}
\hline \multirow{2}{*}{$\begin{array}{c}\text { Variable } \\
\text { Ad Expenditures (Dollars in } \$ 1,000,000)\end{array}$} & \multicolumn{3}{|c|}{$\begin{array}{c}\text { Online WOM } \\
\text { Estimate (Std. Error) }\end{array}$} & \multicolumn{3}{|c|}{$\begin{array}{c}\text { Web Traffic } \\
\text { Estimate (Std. Error) }\end{array}$} \\
\hline & 0.287 & $(0.000)$ & $* *$ & 0.053 & $(0.001)$ & $* *$ \\
\hline \multicolumn{7}{|c|}{ Product Placement Modality (weighted by program ratings in 1,000,000 viewers) } \\
\hline Implied visual & -0.000 & $(0.000)$ & & 0.000 & $(0.001)$ & \\
\hline Direct visual & -0.000 & $(0.000)$ & $*$ & 0.001 & $(0.001)$ & \\
\hline Verbal & 0.023 & $(0.001)$ & $* *$ & 0.005 & $(0.001)$ & $* *$ \\
\hline Audiovisual & 0.014 & $(0.001)$ & $* *$ & 0.008 & $(0.003)$ & $* *$ \\
\hline \multicolumn{7}{|c|}{ Product Placement Modality and Advertising Interactions } \\
\hline Implied visual $\times$ Ad spend & -0.002 & $(0.001)$ & $* *$ & -0.003 & $(0.002)$ & \\
\hline Direct visual $\times$ Ad spend & -0.003 & $(0.000)$ & $* *$ & 0.007 & $(0.001)$ & $* *$ \\
\hline Verbal $\times$ Ad spend & -0.076 & $(0.001)$ & $* *$ & -0.014 & $(0.002)$ & $* *$ \\
\hline Audiovisual $\times$ Ad spend & 0.071 & $(0.001)$ & $* *$ & -0.022 & $(0.006)$ & $* *$ \\
\hline \multicolumn{7}{|l|}{ Other Model Parameters } \\
\hline Dependent variable lag & 0.505 & $(0.000)$ & $* *$ & 0.085 & $(0.001)$ & $* *$ \\
\hline \multicolumn{7}{|l|}{ Decay parameters } \\
\hline$\delta_{I}$ (implied visual) & 1.000 & $(0.007)$ & $* *$ & 0.488 & $(0.002)$ & $* *$ \\
\hline$\delta_{2}($ direct visual $)$ & 1.000 & $(0.005)$ & $* *$ & 0.652 & $(0.002)$ & $* *$ \\
\hline$\delta_{3}($ verbal $)$ & 0.122 & $(0.001)$ & $* *$ & 0.975 & $(0.006)$ & \\
\hline$\delta_{5}$ (audiovisual) & 0.630 & $(0.000)$ & $* *$ & 0.000 & $(0.052)$ & \\
\hline$\delta_{6}($ advertising $)$ & 0.133 & $(0.000)$ & $* *$ & 0.626 & $(0.001)$ & $* *$ \\
\hline $\mathrm{SD}$ & 0.513 & $(0.000)$ & $* *$ & 0.312 & $(0.000)$ & $* *$ \\
\hline $\begin{array}{l}\text { Fixed effects for brand, month, and day-time } \\
\text { block }\end{array}$ & \multicolumn{3}{|c|}{ Yes } & \multicolumn{2}{|c|}{ Yes } & \\
\hline
\end{tabular}

Note: Model estimates are presented with standard errors in parenthesis. Estimates with p-values $\leq 0.10$ are indicated by $(*)$. Estimates with $p$-values $\leq 0.05$ are indicated by $(* *)$. 
Table 7: Model Comparison for Placement-level Analysis

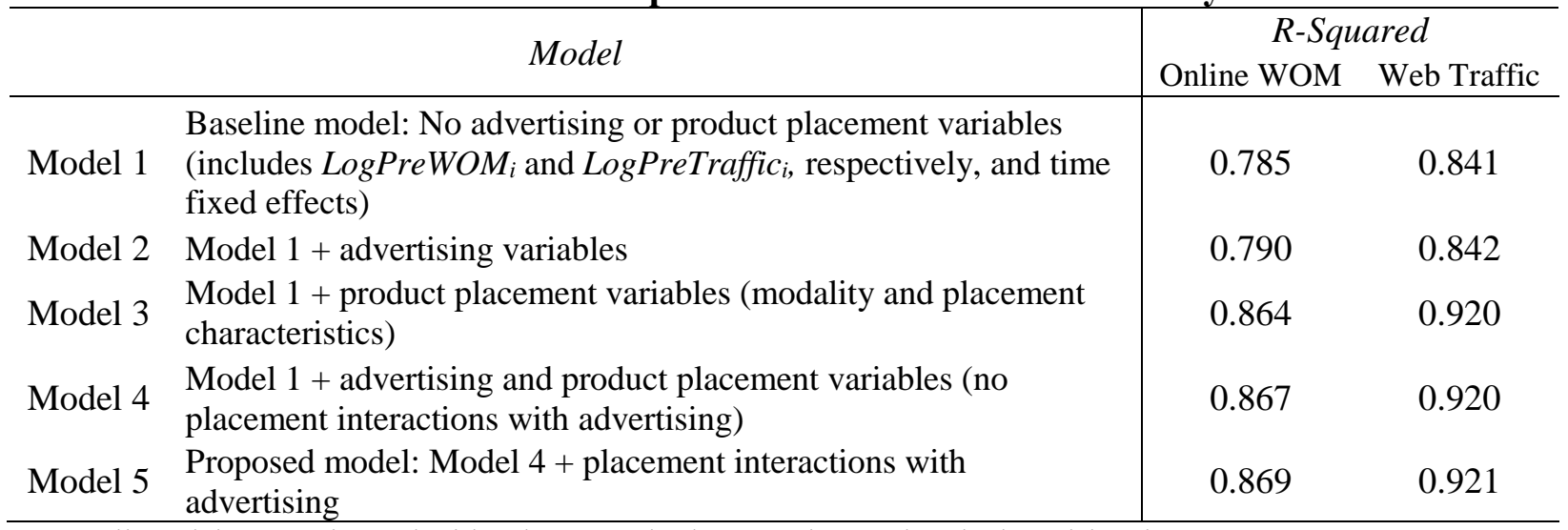

Note: All models are estimated with robust standard errors clustered at the brand-level.

Table 8: Relationship among Product Placement, Television Advertising, and Brand-related Social Media Activity and Website Traffic in Placement-level Analysis

\begin{tabular}{ccc}
\hline Variable & $\begin{array}{c}\text { Online WOM } \\
\text { Estimate (Std. Error) }\end{array}$ & $\begin{array}{c}\text { Web Traffic } \\
\text { Estimate (Std. Error) }\end{array}$ \\
\hline LogPreWOM $_{i} /$ LogPreTraffic $_{i}$ & $0.379(0.036)$ & $* *$ \\
\hline
\end{tabular}

Product Placement Modality (Baseline: Implied visual; weighted by audience size in 1,000,000 viewers)

Direct visual

Verbal

Audiovisual

\section{Product Placement Characteristics}

Character interaction: Fictional

Character interaction: Real

Placement length (seconds)

Cumulative placement

Cumulative placement ${ }^{2}$

Program pod

Sponsor

Ad Expenditures (Dollars in $\$ 1,000,000$ )

Ad spend pre-placement (same channel)

Ad spend post-placement (same channel)

Ad spend pre-placement (other broadcast channels)

Ad spend post-placement (other broadcast channels)

$$
\begin{aligned}
-0.000(0.004) & \\
0.029(0.009) & * * \\
0.049(0.027) & *
\end{aligned}
$$

$-0.003(0.020)$

$0.095(0.038) * *$

$-0.000(0.000)$

$0.009(0.006)$

$-0.001(0.000) * *$

$-0.006(0.001) * *$

$-0.033(0.056)$
$0.006(0.003) *$

$0.016(0.008) * *$

$0.002(0.010)$

$-0.025(0.031)$

$-0.033(0.044)$

$0.000(0.000)$

$0.009(0.006)$

$-0.000(0.000)$

$-0.001(0.002)$

$-0.110(0.046) * *$

$0.168(0.203)$

$0.326(0.407)$

$0.036(0.044)$

$0.254(0.248)$

Product Placement Modality and Advertising Interactions (same channel ad spend)

Direct visual $\times$ Ad spend pre-placement

Verbal $\times$ Ad spend pre-placement

Audiovisual $\times$ Ad spend pre-placement

Direct visual $\times$ Ad spend post-placement

Verbal $\times$ Ad spend post-placement

Audiovisual $\times$ Ad spend post-placement
$0.095(0.063)$

$-0.006(0.059)$

$-0.154(0.074) * *$

$-0.139(0.048) \quad * *$

$-0.264(0.115) * *$

$0.064(0.074)$
$0.001(0.047)$

$-0.247(0.102) * *$

$0.048(0.076)$

$-0.109(0.059) *$

$-0.207(0.069) * *$

$-0.046(0.052)$

Note: Estimates with $\mathrm{p}$-values $\leq 0.10$ are indicated by $(*)$. Estimates with $\mathrm{p}$-values $\leq 0.05$ are indicated by $(* *)$. Cumulative placement is a placement stock measure, as described in Table 6. Online Appendix Tables 3-5 show the estimates of the time, brand, and program fixed effects. 
Table 9: Scenario Analysis for Placement-level Analysis

\begin{tabular}{|c|c|c|c|c|c|c|c|c|}
\hline \multirow{3}{*}{$\begin{array}{l}\text { Placement } \\
\text { Modality }\end{array}$} & \multicolumn{8}{|c|}{ Ad Spend } \\
\hline & \multicolumn{2}{|c|}{$\begin{array}{l}\text { No ad spend pre- } \\
\text { and post-placement }\end{array}$} & \multicolumn{2}{|c|}{$\begin{array}{l}\text { Average ad spend } \\
\text { pre- and post- } \\
\text { placement }\end{array}$} & \multicolumn{2}{|c|}{$\begin{array}{l}\text { No ad spend pre- } \\
\text { placement and } \\
\text { average ad spend } \\
\text { post-placement }\end{array}$} & \multicolumn{2}{|c|}{$\begin{array}{c}\text { Average ad spend } \\
\text { pre-placement and } \\
\text { no ad spend post- } \\
\text { placement }\end{array}$} \\
\hline & $\begin{array}{l}\text { Online } \\
\text { WOM }\end{array}$ & $\begin{array}{l}\text { Web } \\
\text { Traffic }\end{array}$ & $\begin{array}{l}\text { Online } \\
\text { WOM }\end{array}$ & $\begin{array}{l}\text { Web } \\
\text { Traffic }\end{array}$ & $\begin{array}{l}\text { Online } \\
\text { WOM }\end{array}$ & $\begin{array}{l}\text { Web } \\
\text { Traffic }\end{array}$ & $\begin{array}{l}\text { Online } \\
\text { WOM }\end{array}$ & $\begin{array}{l}\text { Web } \\
\text { Traffic }\end{array}$ \\
\hline & \multicolumn{8}{|c|}{ Ford } \\
\hline Implied visual & 72 & 214 & 74 & 220 & 74 & 218 & 73 & 216 \\
\hline Direct visual & 72 & 249 & 73 & 248 & 73 & 246 & 73 & 251 \\
\hline Verbal & 85 & 316 & 85 & 291 & 85 & 306 & 85 & 301 \\
\hline \multirow[t]{2}{*}{ Audiovisual } & 95 & 228 & 96 & 234 & 97 & 229 & 94 & 233 \\
\hline & \multicolumn{8}{|c|}{ Percentage changes in online behavior relative to implied visual placements } \\
\hline Direct visual & $0 \%$ & $16 \%$ & $0 \%$ & $13 \%$ & $-1 \%$ & $13 \%$ & $0 \%$ & $16 \%$ \\
\hline Verbal & $17 \%$ & $47 \%$ & $16 \%$ & $32 \%$ & $16 \%$ & $40 \%$ & $17 \%$ & $39 \%$ \\
\hline \multirow[t]{2}{*}{ Audiovisual } & $31 \%$ & $6 \%$ & $30 \%$ & $6 \%$ & $31 \%$ & $5 \%$ & $29 \%$ & $8 \%$ \\
\hline & \multicolumn{8}{|c|}{ Microsoft } \\
\hline Implied visual & 66 & 33,250 & 67 & 33,433 & 67 & 33,388 & 66 & 33,294 \\
\hline Direct visual & 66 & 34,314 & 67 & 34,241 & 66 & 34,194 & 66 & 34,361 \\
\hline Verbal & 78 & 36,395 & 78 & 35,675 & 78 & 36,016 & 78 & 36,050 \\
\hline \multirow[t]{2}{*}{ Audiovisual } & 86 & 33,674 & 88 & 33,822 & 89 & 33,705 & 86 & 33,791 \\
\hline & \multicolumn{8}{|c|}{ Percentage changes in online behavior relative to implied visual placements } \\
\hline Direct visual & $0 \%$ & $3 \%$ & $-1 \%$ & $2 \%$ & $-1 \%$ & $2 \%$ & $0 \%$ & $3 \%$ \\
\hline Verbal & $18 \%$ & $9 \%$ & $16 \%$ & $7 \%$ & $16 \%$ & $8 \%$ & $18 \%$ & $8 \%$ \\
\hline \multirow[t]{2}{*}{ Audiovisual } & $31 \%$ & $1 \%$ & $31 \%$ & $1 \%$ & $32 \%$ & $1 \%$ & $31 \%$ & $1 \%$ \\
\hline & \multicolumn{8}{|c|}{ Amazon } \\
\hline Implied visual & 52 & 22,638 & 53 & 22,707 & 53 & 22,707 & 52 & 22,638 \\
\hline Direct visual & 52 & 23,197 & 52 & 23,168 & 52 & 23,168 & 52 & 23,197 \\
\hline Verbal & 59 & 24,279 & 59 & 24,155 & 59 & 24,155 & 59 & 24,279 \\
\hline \multirow[t]{2}{*}{ Audiovisual } & 64 & 22,861 & 65 & 22,889 & 65 & 22,889 & 64 & 22,861 \\
\hline & \multicolumn{8}{|c|}{ Percentage changes in online behavior relative to implied visual placements } \\
\hline Direct visual & $0 \%$ & $2 \%$ & $-1 \%$ & $2 \%$ & $-1 \%$ & $2 \%$ & $0 \%$ & $2 \%$ \\
\hline Verbal & $14 \%$ & $7 \%$ & $12 \%$ & $6 \%$ & $12 \%$ & $6 \%$ & $14 \%$ & $7 \%$ \\
\hline Audiovisual & $23 \%$ & $1 \%$ & $24 \%$ & $1 \%$ & $24 \%$ & $1 \%$ & $23 \%$ & $1 \%$ \\
\hline
\end{tabular}

Note: These online behaviors correspond to the volume of online activity in the ten-minute window post-placement. To extend our web traffic estimates beyond comScore's panel of 100,000 active U.S internet users to the U.S. population as a whole, we extrapolate our web traffic estimates to the U.S Census's estimated number of households in the U.S. with internet in 2015 (91,256,576 households). 
Figure 1: Volume of WOM and Web Traffic for Brands across Placement Modality

WOM for Brands in Implied Visual Placements

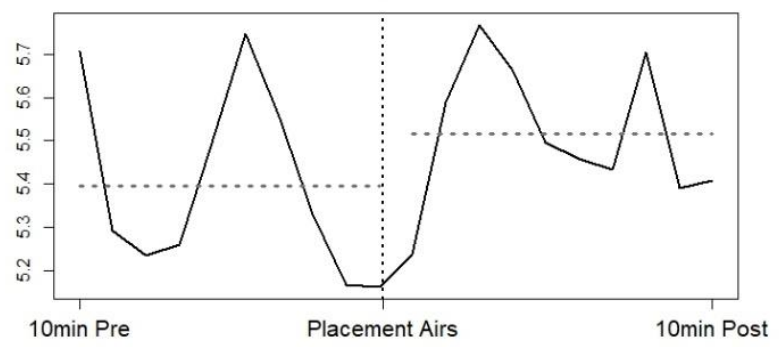

Web Traffic for Brands in Implied Visual Placements

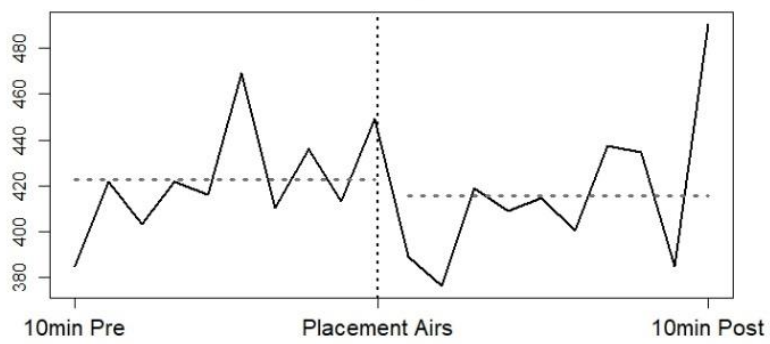

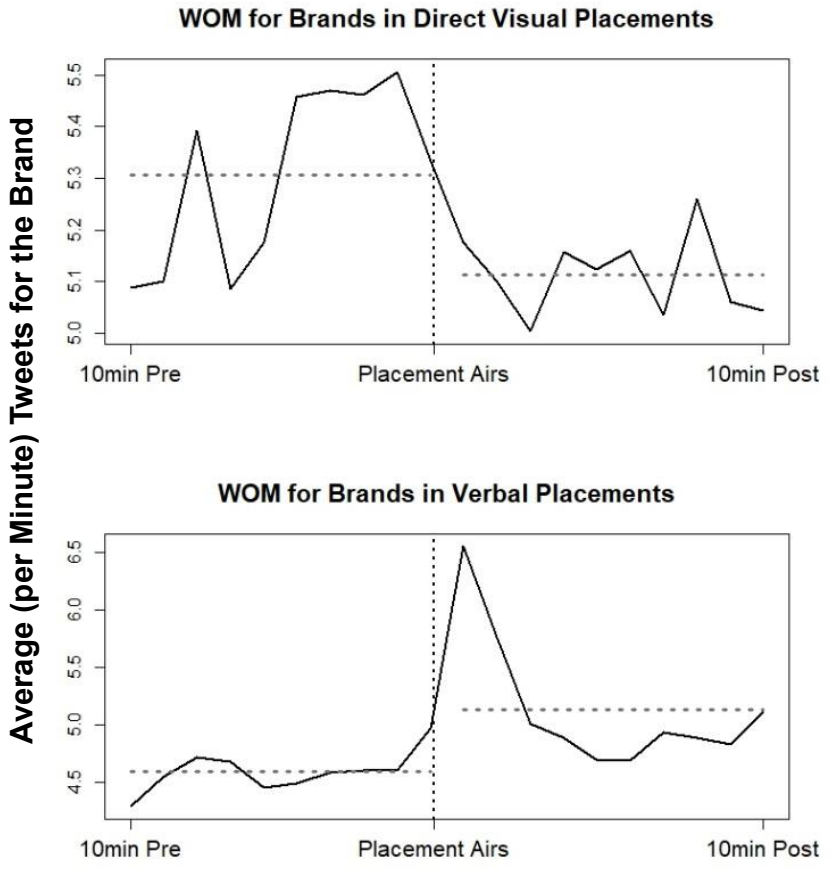
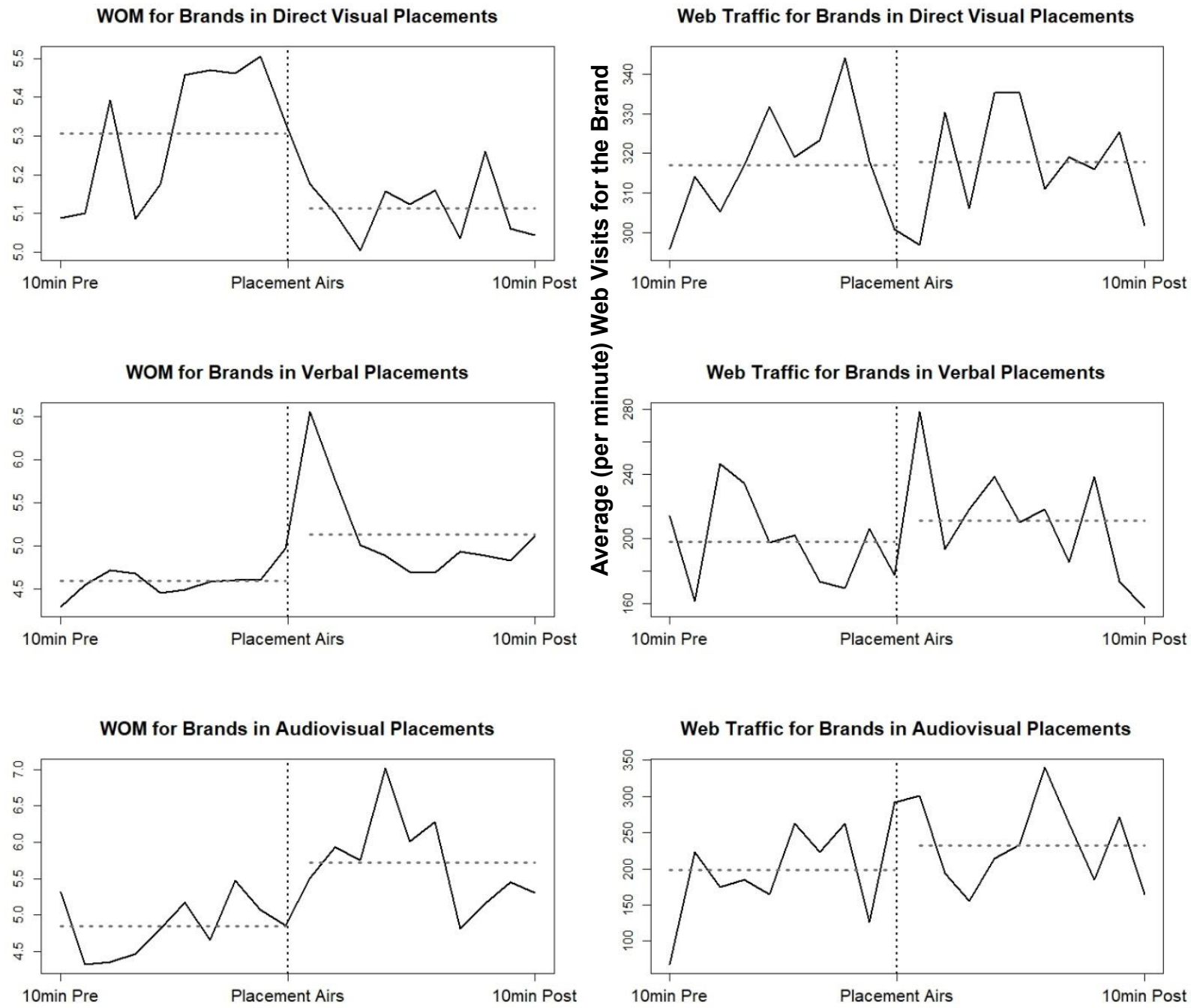

Note: The horizontal dashed lines show the mean values of WOM, as measured by Twitter mentions, or web visits, respectively, in the pre-placement and post-placement time windows. The y-axis in column 1 (column 2) shows the average per-minute Tweets about the brand (average per-minute web visits to the brand's website). To extend our web traffic estimates beyond comScore's panel of 100,000 active U.S internet users to the U.S. population as a whole, we extrapolate our web traffic estimates to the U.S Census's estimated number of households in the U.S. with internet in 2015 (91,256,576 households). 